\title{
Dynamic Behavior of Coal-Fired Power Plants with Postcombustion $\mathrm{CO}_{2}$ Capture
}

\author{
Kai Wellner, Thomas Marx-Schubach,* and Gerhard Schmitz \\ Institute of Thermo-Fluid Dynamics, Hamburg University of Technology, Denickestrasse 17, 21073 Hamburg, Germany
}

Supporting Information

ABSTRACT: The combined operation of postcombustion $\mathrm{CO}_{2}$ capture and a power plant is a complex process with significant mutual interactions. Although the application of $\mathrm{CO}_{2}$ capture imposes an efficiency penalty on the power plant, it also provides the opportunity to operate the power plant in a more flexible way. To analyze this process, a detailed model of a postcombustion capture plant is developed and validated with measurement data. Afterward, the model is coupled to the model of a hard coal-fired power plant to study the effects of a joint operation. In a case study scenario, the steam extraction of the carbon capture plant is reduced by $50 \%$ to increase the power generation of the power plant. The results indicate that it is possible to provide primary frequency control by using this mode of operation.

\section{INTRODUCTION}

To stop global warming and moderate its effects, ambitious targets for the mitigation of carbon dioxide $\left(\mathrm{CO}_{2}\right)$ emissions have to be set. The Intergovernmental Panel on Climate Change (IPCC) demands a reduction in $\mathrm{CO}_{2}$ emissions of $80 \%$ by 2050 compared to the reference year $1990 .{ }^{1}$ According to the International Energy Agency (IEA), one important tool for the short- and midterm reduction of $\mathrm{CO}_{2}$ is carbon capture and storage (CCS), which means the removal of $\mathrm{CO}_{2}$ from power plant flue gases with a subsequent compression and storage in underground formations. It is estimated that by 2035 CCS can have a $17 \%$ share in the overall $\mathrm{CO}_{2}$ reduction. ${ }^{2}$

Many ways to separate the $\mathrm{CO}_{2}$ are available in various stages of technological maturity. The technology of postcombustion $\mathrm{CO}_{2}$ capture has been extensively studied in recent years. ${ }^{3}$ Several lab and pilot-scale plants have been set up and are operated worldwide to increase knowledge about the process itself and its behavior. This advance is also supported by computer models that are validated against measurement data of such pilot plants. However, most literature on the modeling and simulation of postcombustion capture plants perform only a steady-state validation; a dynamic validation for a model of reduced complexity; or a validation only of particular parts of the capture plant, such as the absorber. ${ }^{4-7}$ Furthermore, very little is known about the actual performance of a full-scale capture plant when operated in combination with a power plant.

To close this gap, the model of a postcombustion capture plant (PCC) attached to a coal-fired power plant is presented in this study. Because the coupling of a power plant and a separation unit can introduce significant mutual interactions, a thorough analysis of the overall process is essential. The focus of the study is set on the transient behavior of the $\mathrm{CO}_{2}$ capture

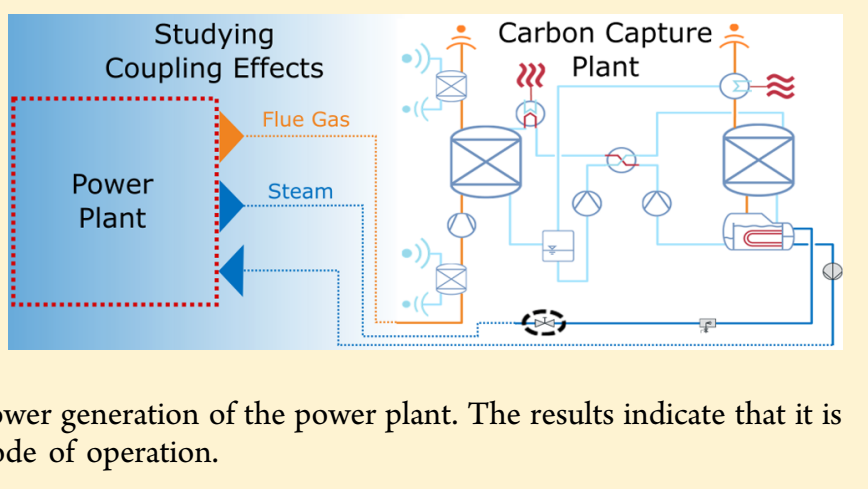

plant and its influence on the power plant process because the general behavior of a coal-fired power plant is already wellknown. For this purpose, the model of a PCC plant is developed and validated by itself before it is coupled to a water-steam cycle.

In addition to the demand of reducing $\mathrm{CO}_{2}$ emissions, another challenge will become yet more important in the future. The increasing amount of renewable energies in many regions imposes new operational requirements on power plants. Montañés et al. ${ }^{8}$ determined market opportunities and technical requirements of power plants including a carbon capture plant for providing ancillary services in four different balancing markets inside the EU. Hence, solutions for the operation of flexible power plants with carbon capture processes under these conditions and restrictions have to be found. To achieve this goal, validated dynamic models for this type of process are needed. A first approach for providing primary or secondary frequency control is therefore presented in a case study in this article.

First, an overview of the process of postcombustion capture using a water-based amine solvent is given. The modeling approach is explained followed by an in-depth model validation of the PCC. For this purpose, dynamic measurement data of a pilot plant in Heilbronn, Germany, are available. After that, the model of an industrial scale PCC attached to a $600 \mathrm{MW}$ power plant is introduced and a case study is presented. In this study the steam for the reboiler heating, which is extracted from the power plant process, is throttled. It is discussed whether this

Received: July 19, 2016

Revised: October 27, 2016

Accepted: October 27, 2016

Published: November 8, 2016 
measure is appropriate to provide control power or if any restrictions in terms of control objectives or transient behavior of the process exist.

\section{PROCESS DESCRIPTION}

Several technologies for the capture of $\mathrm{CO}_{2}$ from power plant flue gases are available, namely, precombustion, oxyfuelcombustion, and postcombustion. This study focuses on the postcombustion capture because it is the most mature technology. In this section, brief descriptions of the PCC process and the power plant process are given. A more detailed description of the characteristics of the coupling of both processes is given in section 5 .

2.1. Postcombustion $\mathrm{CO}_{2}$ Capture Process. For the postcombustion capture, multiple different technologies such as absorption, adsorption, or membrane separation can be applied. In this study, a separation process based on the reactive absorption of $\mathrm{CO}_{2}$ in an aqueous washing solution is used. To enhance the solvent's capture capacity, chemical additives are applied. There is a wide range of additives, such as primary, secondary, and tertiary amines; polyamines; alkali salts; and ionic liquids. $^{9-11}$ However, in most plants, primary amines are used because they are considered as baseline solvents because of their extensive use for many years in the gas sweetening industry. This is the reason why here a $30 \mathrm{wt} \%$ monoethanolamine (MEA) solution is used. The advantage of the PCC process is that it can be retrofitted to existing power plants because it directly treats the flue gas before it is released to the atmosphere. A disadvantage of this process is the low $\mathrm{CO}_{2}$ partial pressure in the flue gas that leads to a high energy demand.

The process flow diagram of a PCC plant is shown in Figure 1. The flue gas enters the plant through a flue gas cooler where

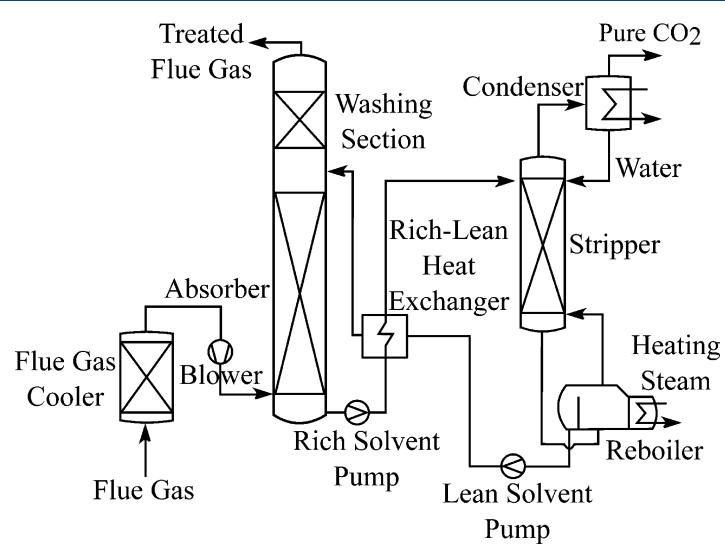

Figure 1. PFD of a postcombustion capture plant.

it is cooled to temperatures around $35{ }^{\circ} \mathrm{C}$. After that, the flue gas passes through the absorber where the $\mathrm{CO}_{2}$ is removed in an exothermic reaction. Before the cleaned flue gas is released to the atmosphere it flows through a washing section, where it is cooled one more time to close the water balance and to prevent solvent slip. Downstream, the absorber-rich $\left(\mathrm{CO}_{2}-\right.$ loaded) solvent is pumped trough a cross-flow heat exchanger where it is preheated by the regenerated $\left(\mathrm{CO}_{2}\right.$-lean $)$ solvent to minimize the energy input. In the stripper, the $\mathrm{CO}_{2}$ is removed from the solvent by adding energy in the form of heat to the kettle type reboiler. The solvent is located on the shell side of the reboiler, whereas the steam flows through the tube side to heat the solvent. At the top of the stripper, the $\mathrm{CO}_{2}$ product passes a condenser where remaining water is removed. The lean solvent from the reboiler is fed back to the absorber.

2.2. Power Plant Process. Figure 2 visualizes a process flow diagram of a simplified water-steam cycle. In the steam

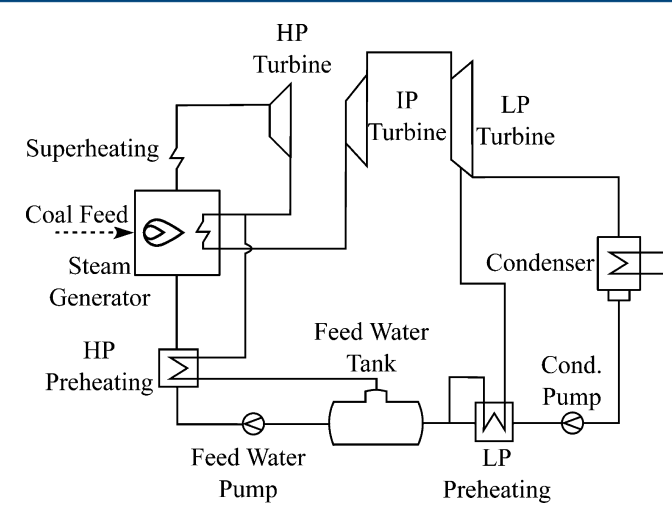

Figure 2. PFD of a simplified water-steam cycle.

generator, the feedwater is evaporated and superheated before it passes the high-pressure (HP) turbine. After that a part of the steam is diverted to heat the feedwater in the high-pressure preheater. The rest of the steam is reheated and fed through the intermediate-pressure (IP) and low-pressure (LP) turbines. In the latter, a part of the steam is used to heat the condensate in the low-pressure preheater. The major part of the steam is condensed and pumped through the low-pressure preheater into the feedwater tank. The cycle is closed by the feedwater being pumped through the high-pressure preheater into the steam generator.

\section{MODELING}

To investigate the dynamic behavior of a full-scale coal-fired power plant equipped with $\mathrm{CO}_{2}$ capture, evaluate the results, and give recommendations regarding the mode of operation, computer simulations are indispensable. In this case, where the subprocesses originate from different fields of engineering, it is convenient to be able to instantiate models from a model library. Especially, the ability to reuse, modify, and extend the models is essential to keep the programming effort within reasonable bounds. Because the overall model is composed of a complex arrangement of several subcomponents, it is not feasible to define in- and outputs of these components a priori. Hence, it is desirable to use an acausal modeling approach where the equations do not have to be arranged in a specific sequence. All these requirements are fulfilled by the equationbased and object-oriented modeling language Modelica, which is the reason it has been used during this study. ${ }^{12}$

The Thermalseparation model library provides the basis for the models of the PCC. For the simulation of watersteam cycles, the existing model library $\mathrm{ClaRa}$ is used. Both libraries and the modifications that have been done are addressed in the following subsections.

3.1. Models of the $\mathrm{CO}_{2}$ Capture Process. The models of the capture process originate from the ThermalSeparation model library which supplies models for the simulation of absorption and rectification processes. These models are augmented such that they allow the simulation of a carbon capture plant. The modeling of the separation columns follows a first-principles approach in which the column is axially divided 
into stages. For each stage and each fluid constituent, separate mass balances for liquid and vapor phases are set up. Thus, one energy balance is used for each phase and stage, respectively. The model allows for the use of rate-based or equilibrium-based approaches regarding the heat and mass transfer across the phase boundary. If chemical reactions are considered, they are accounted for in the liquid phase. The modularity of the column model allows the user to choose between several different correlations for pressure loss, hold up, and heat loss. A more detailed description of the underlying equations and correlations is presented by Dietl ${ }^{13}$ and Dietl et al. ${ }^{14}$ Regarding the actual model of the PCC, the following assumptions hold:

- The absorber vapor medium (flue gas) consists of $\mathrm{CO}_{2}$, $\mathrm{H}_{2} \mathrm{O}, \mathrm{N}_{2}$, and $\mathrm{O}_{2}$.

- The stripper and reboiler vapor media consist of $\mathrm{CO}_{2}$ and $\mathrm{H}_{2} \mathrm{O}$.

- The liquid medium in all components of the PCC process consists of $\mathrm{CO}_{2}, \mathrm{H}_{2} \mathrm{O}$ and MEA; MEA is considered nonvolatile.

- Ideal gas behavior is assumed.

- The phase equilibrium and the chemical reactions (including the heat of reaction) are modeled in a joint approach according to Oexmann, ${ }^{9}$ where the phase equilibrium of the $\mathrm{CO}_{2}$ is enhanced such that it also accounts for removal of $\mathrm{CO}_{2}$ from the flue gas through the chemical reactions. Furthermore, the bulk phases are assumed to be in thermodynamic equilibrium with the phase boundary.

- To match the solvent's rich loading at the absorber outlet, a calibration factor in the equation of the phase equilibrium is used. This measure is required only in the absorber to counteract the overprediction of the separation efficiency due to the equilibrium assumption. It is adjusted by matching the rich loading to the simulation of the same process with a rate-based approach conducted with Aspen Plus. ${ }^{15}$ In the stripper model, the use of a calibration factor is not necessary because the thermodynamic equilibrium is attained at stripper conditions.

- Liquid density and heat capacity of the MEA solution can be described by using empirical correlations developed by Oexmann. ${ }^{9}$

- The components of the capture cycle are adiabatic.

- The column pressure drop and liquid hold-up are calculated using the correlations developed by Stichlmair et al. ${ }^{16}$

- No chemical reactions take place in components other than the absorber and stripper columns.

- The volume of the pipes is small compared to the rest of the components and can therefore be neglected.

- Heat exchangers with constant heat-transfer coefficients are used.

The resulting model is used to compose a model of an entire postcombustion capture plant. To underline the validity of this model and to be able to expand its informative value to an industrial scale, it needs to be thoroughly validated against measurement data. This validation is performed in section 4 .

3.2. Models of the Power Plant Process. The models for the simulation of the water-steam cycle of the power plant are taken from the already existing model library ClaRa. ${ }^{17}$ This library provides models for the simulation of thermohydraulic processes like pipes, valves, turbomachinery, heat exchangers, and coal mills. Furthermore, it contains submodels that can be utilized to model a detailed steam generator that is subdivided into different burner levels, flame rooms with thermal radiation, and flame rooms containing tube bundles for convective heat transfer. This feature is especially important, because the overall transient behavior of the power plant is predominantly influenced by the steam generator which therefore has to be modeled with an adequate level of detail. Because the models provided by this library are already validated, an additional validation is not required at this point. The main operation parameters of the power plant modeled and used in the case study are presented in Table $1 .^{18}$

Table 1. Main Operation Parameters of Power Plant ${ }^{18}$

\begin{tabular}{ll}
\multicolumn{1}{c}{ parameter } & \multicolumn{1}{c}{ value } \\
plant capacity & $600 \mathrm{MW}$ \\
net capacity (without CCS) & $555 \mathrm{MW}$ \\
net efficiency (without CCS) & $45.9 \%$ \\
live steam condition & $285 \mathrm{bar} / 600{ }^{\circ} \mathrm{C} / 620{ }^{\circ} \mathrm{C}$ \\
type of boiler & benson tower type with vertical tubing \\
steam turbine & 3 -casing steam turbine; single reheat \\
condenser pressure & 45 mbar \\
preheater & 8 preheater and external desuperheater \\
\hline
\end{tabular}

\section{VALIDATION OF THE $\mathrm{CO}_{2}$ CAPTURE PLANT MODEL}

In this section a short description of the pilot plant that supplies the measurement data for the validation is given. After that, the conducted experiment is described and a steady state as well as a transient validation of the model is performed.

4.1. Pilot Plant Heilbronn. For the validation of the models from the Thermalseparation library, measurement data of the PCC pilot plant in Heilbronn, Germany, are available. The plant consists of an absorber with a height of 40 $\mathrm{m}$ and a stripper of $25 \mathrm{~m}$. The absorber has five beds with a height of $5 \mathrm{~m}$ each, filled with random packing material. The stripper is equipped with three such beds. Between each bed, collectors and distributors are placed to collect the solvent and evenly distribute it across the subjacent packing. In both columns the packing material is of VSP-25 type. ${ }^{19}$ The plant is fed with flue gas from the adjacent power plant and is capable of scrubbing $1500 \mathrm{Nm}^{3} / \mathrm{h}$, which corresponds to approximately $0.05 \%$ of the actual power plant's flue gases. In contrast to the process depicted in Figure 1, the pilot plant is additionally equipped with an intercooling in the absorber column to maximize its efficiency. In addition, the stripper has a washing section to prevent degradation products from being emitted to the atmosphere. Table 2 shows the nominal operating conditions of the pilot plant. Further information on the plant is given in Rieder and Unterberger. ${ }^{20}$

4.2. Experiments and Validation. First, a steady-state validation is carried out to match the results of the pilot plant for $100 \%$ load. For this purpose, the heat-transfer coefficients of the cross-flow heat exchanger are tuned such that the model provides the same temperature differences between in- and outlets as the pilot plant. Other than this, no adaptations of the model have been made. As an input to the model, the following parameters are set according to the boundary conditions given by the pilot plant:

- The flue gas flow rate into the cooler with its composition and temperature.

- The heat flow rate into the reboiler. 
Table 2. Nominal Operating Point of Pilot Plant

\begin{tabular}{ll}
\multicolumn{1}{c}{ parameter } & \multicolumn{1}{c}{ value } \\
flue gas volume flow rate & $1500 \mathrm{~N} \mathrm{~m}^{3} / \mathrm{h}$ \\
$\mathrm{CO}_{2}$ concentration flue gas & $12.3 \mathrm{~mol} \mathrm{\%}$ \\
flue gas temp. absorber inlet & $40{ }^{\circ} \mathrm{C}$ \\
solvent flow rate & $5.3 \mathrm{~m}^{3} / \mathrm{h}$ \\
Solvent temp. absorber inlet & $35{ }^{\circ} \mathrm{C}$ \\
MEA concentration & $30 \mathrm{wt} \%$ \\
stripper pressure & $2 \mathrm{bar}$ \\
$\mathrm{CO}_{2}$ product temperature & $23{ }^{\circ} \mathrm{C}$ \\
$\mathrm{CO}_{2}$ target capture rate & $90 \%$ \\
\hline
\end{tabular}

- The pressures at the top of each column.

- The solvent flow rate of the lean solvent pump. The rich solvent pump is used to control the level of the absorber sump.

Furthermore, the model of the absorber comprises 20 equilibrium stages and that of the stripper 10 stages. Table 3

Table 3. Steady-State Validation for $100 \%$ Load

\begin{tabular}{lll}
\multicolumn{1}{c}{ parameter } & model & pilot plant \\
$X_{\mathrm{CO}_{2}}(\%)$ & 89.4 & 89.8 \\
$\dot{m}_{\mathrm{CO}_{2} \text { str }}(\mathrm{kg} / \mathrm{h})$ & 310.8 & 305.2 \\
$q_{\text {spec }}\left(\mathrm{MJ} / \mathrm{kg}_{\mathrm{CO}_{2}}\right)$ & 3.67 & 3.74 \\
$\alpha_{\mathrm{CO}_{2} \text {,rich }}\left(\mathrm{mol}_{\mathrm{CO}_{2}} / \mathrm{mol}_{\mathrm{MEA}}\right)$ & 0.53 & 0.42 \\
$\alpha_{\mathrm{CO}_{2} \text { lean }}\left(\mathrm{mol}_{\mathrm{CO}_{2}} / \mathrm{mol}_{\mathrm{MEA}}\right)$ & 0.26 & 0.18 \\
$\Delta \alpha\left(\mathrm{mol}_{\mathrm{CO}_{2}} / \mathrm{mol}_{\mathrm{MEA}}\right)$ & 0.27 & 0.24 \\
$\Delta p_{\text {abs }}(\mathrm{mbar})$ & 68.5 & 68.8 \\
$\Delta p_{\text {str }}(\mathrm{mbar})$ & 1.3 & 0.8 \\
$T_{\text {reb }}\left({ }^{\circ} \mathrm{C}\right)$ & 122.0 & 115.9 \\
\hline
\end{tabular}

shows selected variables that are obtained by simulation and compared to measurements of the pilot plant. The capture rate is defined as the relative amount of $\mathrm{CO}_{2}$ that is absorbed in the absorption unit. It is calculated as shown in eq 1 .

$$
X_{\mathrm{CO}_{2}}=1-\frac{\dot{N}_{\mathrm{CO}_{2}, \mathrm{Abs}, \text { out }}}{\dot{N}_{\mathrm{CO}_{2}, \mathrm{Abs}, \text { in }}}
$$

The pressure loss in both columns is measured with a differential pressure sensor. Thermocouples are utilized to measure all temperatures in the plant. The $\mathrm{CO}_{2}$ concentrations at the absorber inlet and outlet are measured with infrared spectroscopy, and the $\mathrm{CO}_{2}$ loading of the solvent is measured offline by titration. Excluding the measurement of the $\mathrm{CO}_{2}$ concentration in the flue gas, all other measured values are determined without redundancy. Unfortunately, the accuracies of the measurement devices that are installed in the plant are unknown; therefore, no detailed, quantitative statements about measurement error can be made. It is assumed that the accuracies are within the common limits of industrial measurement appliances.

The target capture rate, $X_{\mathrm{CO}_{2}}$, of the pilot plant is $90 \%$, which is matched very well by the model. This also applies to the separated $\mathrm{CO}_{2}$ mass flow rate, $\dot{m}_{\mathrm{CO}_{2} \text {,str }}$ that exits the stripper and the specific heat consumption, $q_{\text {spec }}$. To accurately match the specific heat consumption is of high importance because in the superordinate power plant process it is ultimately responsible for the efficiency penalty caused by the steam tapping for the solvent regeneration. Both rich loading, $\alpha_{\mathrm{CO}_{2} \text {,rich }}$ and lean loading, $\alpha_{\mathrm{CO}_{2} \text {, lean }}$, show significant deviations from the measurements. This can be explained by an inaccuracy in the empirical correlation of the thermodynamic equilibrium and by the heat of reaction for the absorption and desorption reaction inside the columns. This conclusion is also supported by the mismatch of the reboiler temperature, $T_{\text {reb}}$, that is directly related to the loading of the solvent. Nevertheless, rich and lean loading are overpredicted in a way that the working capacity, which is defined as the difference of both values, still matches the measurement quite well. This is of major importance because the working capacity determines how much $\mathrm{CO}_{2}$ can be captured in the absorber. The pressure losses, $\Delta p$, in both columns also match fairly well. All in all, it can be concluded that the model predicts the steady-state behavior of the pilot plant at $100 \%$ load accurately. This steady-state validation has also been carried out for $70 \%$ and $50 \%$ load of the plant. The results are given in the Supporting Information for the sake of conciseness. They also support the given statement that the simulation results match the experiments to a very high extent.

In the scenario for the dynamic validation, which is presented in the following, the pilot plant is operated at $70 \%$ load. Then, at $t=0 \mathrm{~s}$, the flue gas flow rate is abruptly increased by $30 \%$. Simultaneously, the heat flow rate into the reboiler is adapted such that a $\mathrm{CO}_{2}$ capture rate of $90 \%$ is maintained. The solvent flow rate remains constant throughout the experiment. The validation of this scenario ensures that the model is capable of correctly reproducing the transient behavior of the pilot plant. In this case, a particular challenge is the change of two parameters at the same time, whose effects on the output variables superimpose on each other. In comparison to the steady-state validation, no additional adjustments are made to the model. Figure 3 shows a comparison of the $\mathrm{CO}_{2}$ capture rate over time for the simulation and the measurement.

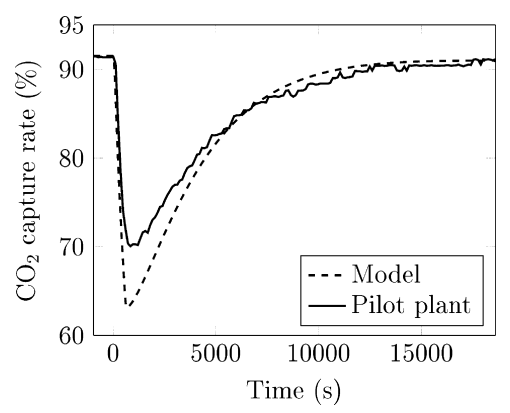

Figure 3. Validation of the capture rate in the absorber column.

At the moment of the perturbation, the capture rate rapidly decreases and afterward returns to its original value with a firstorder transition. This behavior can be attributed to the inertia of the absorber where the increase in flue gas flow rate first hits the entry of the absorber whereas the outlet is still unaffected by the perturbation. The subsequent increase of the capture rate can be explained by the equalization process of temperature and concentration along the absorber profile until a new steady state is reached. In comparison to the measurement, the slope of the model is slightly higher after the perturbation, and also the decline in capture rate is slightly overpredicted by the model. Nevertheless, the time when the minimum capture rate is reached shows a very good agreement, as does the overall transient behavior and the steady-state 
values before and after the perturbation. The minor discrepancies that appear in the slope of the curve can be explained by the assumption that all liquid volumes like sumps, tanks, and the reboiler follow a continuously stirred tank reactor modeling approach. A comparison of the stripped $\mathrm{CO}_{2}$ mass flow rate downstream of the condenser is illustrated in Figure 4.

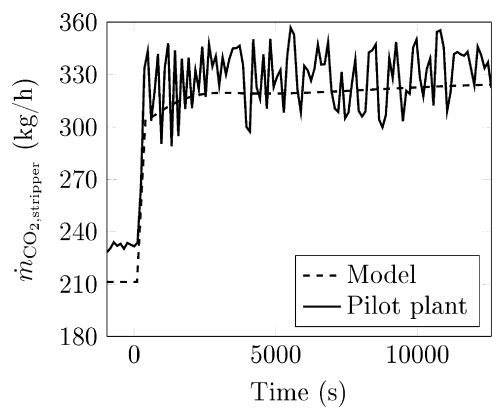

Figure 4. Validation of the $\mathrm{CO}_{2}$ mass flow rate after the stripper column.

As a result of the sudden increase in the reboiler heating, the liquid temperature of the reboiler also rises rapidly. This leads to a higher rate of $\mathrm{CO}_{2}$ desorption which is represented by a fast increase of mass flow rate in the figure. This step is followed by another increase but with a much smaller slope that is caused by the increased flue gas flow rate into the absorber. In contrast to the change in the reboiler heating, this behavior takes effect with a delay because the perturbation first has to pass through the absorber and its sump, the pump, and the cross-flow heat exchanger before it reaches the top of the stripper. Despite the distinct measurement noise, this behavior can also be observed in the measurement.

When the transient behaviors of both columns are compared, it can be observed that the response of the stripper is much faster than that of the absorber. The reason for these different time constants is the large total amount of used solvent in comparison with other carbon capture plants. Most of the solvent content is situated in the absorber and desorber sump and the large intercooling tank. The reason that the stripper reacts much faster is that the rich loading is at its maximum, regardless of the operating conditions of the plant due to an oversized absorption unit. Therefore, the solvent loading in the absorption sump and consequently the solvent input concentration at the top of the stripper is only slightly affected during load changes. On the other hand, it takes a very long time for the lean loading in the desorber sump and the intercooling tank to attain a new equilibrium state. Hence, the overall absorber response is very slow.

All in all, it can be concluded that the agreement between model and pilot plant is good. Now that the validity of the model's results is proven, further studies can be performed.

\section{COUPLED MODEL OF POWER PLANT WITH $\mathrm{CO}_{2}$ CAPTURE}

To be able to understand the transient behavior of the PCC in actual operation, studying its mutual interactions with the power plant is required. ${ }^{21-23}$ For this purpose, the model of a $600 \mathrm{MW}$ hard coal-fired power plant is retro-fitted with a $\mathrm{CO}_{2}$ capture unit. A graphical representation of this model can be found in Figure 5. Because of the restriction in size of the separation columns and their periphery, the PCC consists of two lines in parallel operation. The steam for the regeneration of the loaded solvent is extracted from the crossover pipe between intermediate-pressure and low-pressure turbines as the steam provides optimal thermodynamic conditions at this position. $^{24,25}$ This steam extraction ultimately leads to an efficiency penalty of the power plant because after the intermediate-pressure turbines nearly half of the mass flow rate is diverted to the reboiler which would have passed the low-pressure turbines otherwise. To integrate the PCC, the power plant needs small adaptations. First of all, a pressure maintenance valve is installed downstream of the steam tapping

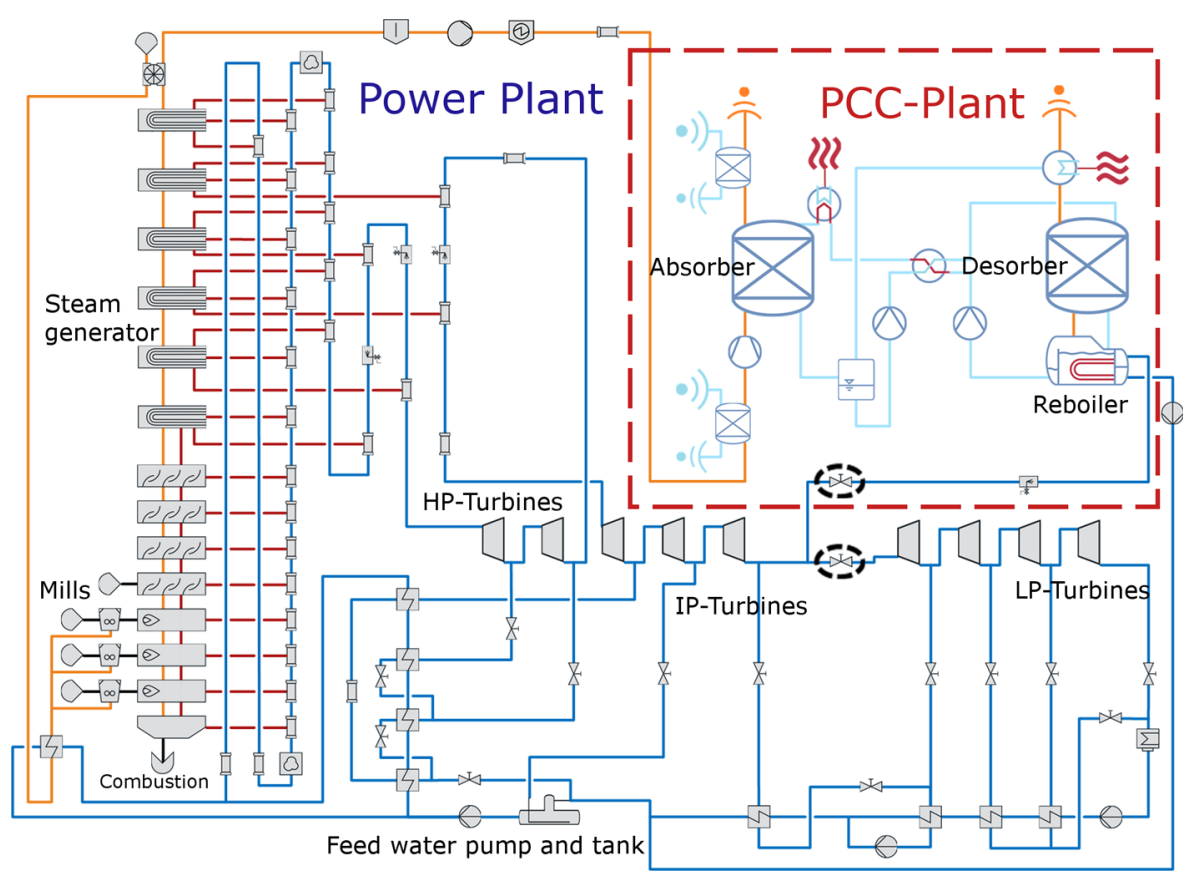

Figure 5. Model of the power plant with postcombustion $\mathrm{CO}_{2}$ capture. 
and upstream of the low-pressure turbines. Its task is to maintain the pressure level needed for the heating of the reboiler, also in part load operation of the power plant where the pressure in the crossover pipe decreases. Second, the steam tapping itself needs a throttling valve to be able to provide the steam with the right conditions for full load of the power plant where the steam in the crossover pipe exceeds the desired pressure and temperature. ${ }^{26,27}$ This valve also serves as actuating variable in case control power shall be provided by throttling the reboiler heating. Finally, an injection cooler is needed behind the throttling valve to desuperheat the steam at full load operation. This measure is necessary because too high steam temperatures lead to thermal degradation of the solvent. $^{28}$ The condensate from the reboiler is fed back to the feedwater tank. The power plant model is operated with a constant coal feed and is controlled by the feedwater pump and the desuperheaters, whereas the PCC runs in feed-forward operation. The pressure maintenance valve and the reboiler throttling valve are marked by a circle. Different from Figure 1, the condensate from the stripper is fed to the absorber sump in the model which is represented as a tank symbol in Figure 5 because of its low temperature.

5.1. Case Description. An increasing share of renewable energy sources in electricity generation leads to huge fluctuations in the power supply. As a consequence, conventional sources like power plants that were designed for base load operation need be operated more flexibly. One option to comply with these requirements is taking advantage of additional actuating variables in power plants equipped with CCS.

In the scenario presented below, initially, the power plant and the PCC run at full load. Full load of the power plant is defined such that the power plant is operated at full thermal capacity. The PCC runs at full load when it has to treat the maximum amount of flue gas, which is also the case when the power plant is operated at full thermal capacity. At time $t=0 \mathrm{~s}$, the mass flow rate of the steam extraction is reduced by $50 \%$ within $150 \mathrm{~s}$. As soon as a new steady state is reached, the valve is opened again and the system returns to its nominal operation point.

5.2. Results. Figure 6 shows the heat transferred from the steam to the solvent of the PCC inside the reboiler. First, it is

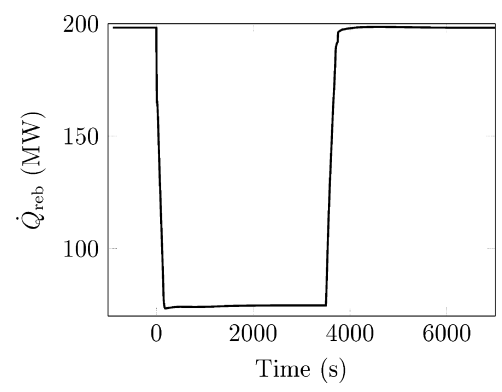

Figure 6. Reboiler heating.

obvious that the mass flow rate of the heating steam does not exactly correlate with the heat input. That is because the extracted steam is overheated and therefore has to be cooled with an injection cooler downstream of the tapping valve. During the throttling, the amount of injected cooling water is not adjusted; thus, a 50\% reduction in heating steam leads to a slightly larger drop in the heat flow rate. As a consequence of throttling the tapping valve, the mass flow rate decreases, which in turn leads to a decreased amount of heat available. This is directly related to a drop of the temperature illustrated in Figure 7.

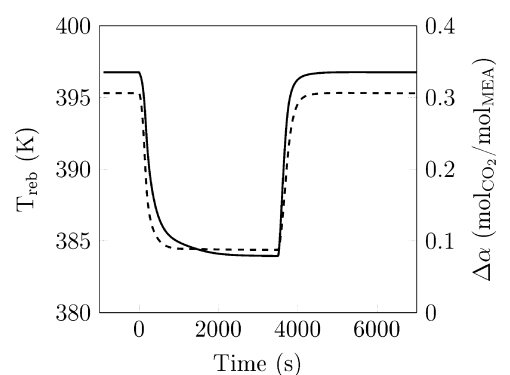

Figure 7. Solvent temperature in reboiler (solid line) and working capacity (dashed line).

The decreased solvent temperature leads to a lower regeneration of the solvent which causes the lean loading at the outlet of the reboiler to increase. Hence, the capacity of the solvent to absorb $\mathrm{CO}_{2}$ decreases (cf. Figure 7) and the capture rate drops to approximately $25 \%$, as shown in Figure 8. After the valve is reopened, the capture rate returns to its original target value of $90 \%$.

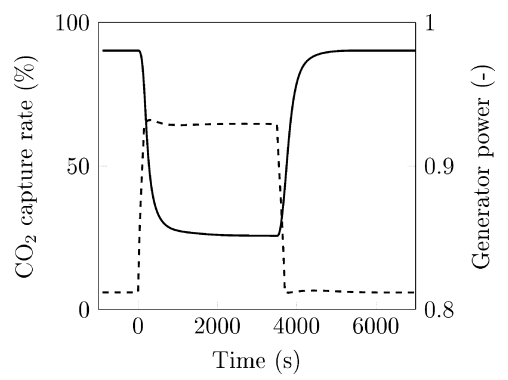

Figure 8. $\mathrm{CO}_{2}$ capture rate (solid line) and relative generator power (dashed line).

The generator power of the power plant, which is also depicted in Figure 8, reacts quite instantaneously to this process. The generator power is normalized to the net capacity of the power plant without PCC. It rises almost linearly with the throttling of the valve. To confirm this, a cut-out of Figure 8 is illustrated in Figure 9. The reason lies in the steam that was redirected to the reboiler. This steam can now pass the lowpressure turbines and raise the generator output by $12 \%$ points. The slight overshoot in generator power is caused by the

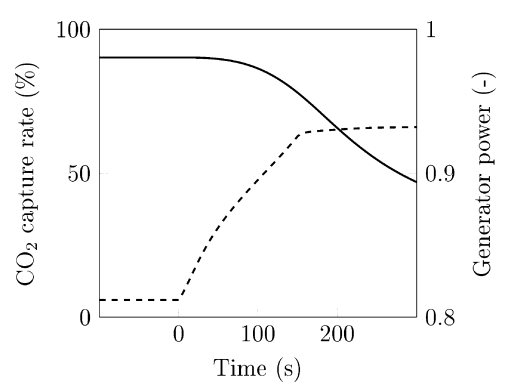

Figure 9. $\mathrm{CO}_{2}$ capture rate (solid line) and relative generator power (dashed line)/cut-out of Figure 8. 
control of the pressure maintenance valve and by the level control in the low-pressure preheaters, which both react to the change in pressure due to the higher mass flow rate through the low-pressure turbines. It appears that the ramp rate for the provision of control power is restricted only by the minimum valve stroke time. The valve stroke time chosen in this example was $t=150 \mathrm{~s}$, which can still be considerably reduced. The reason for the choice of the used ramp time is that this example shall demonstrate the system's general capability to provide primary and secondary control power in a much more flexible way than conventional power plants. Beyond that, current components allow a minimum valve stroke time of around 10 s. ${ }^{29}$ The general capability of providing primary frequency control is demonstrated in Figure 9. The amount of control power can easily be set by adjusting the valve stroke height and time. Furthermore, there is no bottleneck for the provision of control power. Only when returning to nominal operation, the load change rate of the PCC can be limited by the thermal energy transferred in the reboiler because many solvents tend to degrade when exposed to higher temperatures. Here, in the case of MEA, the temperature on the shell side (solvent side) of the reboiler shall not exceed $125{ }^{\circ} \mathrm{C}$, otherwise thermal degradation is inevitable. ${ }^{28}$ As a result, the temperature gradient that can be applied for the reheating of the solvent in the reboiler is limited. This is why an injection cooler is needed behind the throttling valve in case the steam temperature exceeds the saturation temperature (cf. Figure 5).

When compared to the slope of the capture rate, it also shows that the generator output reaches its new steady state much faster. Especially when returning to nominal operation, this means that the target capture rate is reached with a significant delay of approximately 2000 s. During this period, the $\mathrm{CO}_{2}$ emission to the atmosphere is increased and has to be compensated by purchasing $\mathrm{CO}_{2}$ emission certificates. This fact has to be addressed in the individual cost-effective analysis for the provision of control power. If an increased emission is not feasible or not permitted because of regulatory framework, other measures have to be taken. One possibility is to hold an additional tank with lean solvent ready. While the reboiler heating is reduced, this solvent can be used to maintain the target capture rate. However, after the process of providing control power is completed, the excess solvent has to be regenerated with an increased amount of steam which temporarily increases the efficiency penalty of the PCC.

The efficiency penalty of the power plant due to the steam extraction can also be seen in Figure 8. It corresponds to the difference between 1 and the relative generator power before the valve is closed.

All in all, from the simulation results it can be concluded that the possibility to throttle the reboiler valve is a good measure to rapidly increase the generator output.

\section{CONCLUSION AND OUTLOOK}

This paper presents a detailed model of a $\mathrm{CO}_{2}$ capture process coupled to a power plant. The validity of the PCC model's results is illustrated by comparison with measurement data from a pilot-scale plant in Heilbronn, Germany. Both steadystate and transient results show good agreement. Afterward, the validated model is coupled to the model of a hard coal-fired power plant. It can be shown that the reboiler valve is a good actuating variable to provide control power in a fast and reliable way.
Ongoing and future research focuses on modeling the startup of PCC and power plant. The goal is to optimize start-up procedures and to reduce the downtime of the processes. Another important aspect is the control of both processes combined. A highly complex process like this needs a sophisticated control strategy that integrates both processes in a joint approach. A first step in that direction is taken by Gottelt et al. ${ }^{30}$ using the models presented in this paper. The authors implement a model-based control strategy based on existing directives and extend it to be also used for power plants with postcombustion $\mathrm{CO}_{2}$ capture.

\section{ASSOCIATED CONTENT}

\section{Supporting Information}

The Supporting Information is available free of charge on the ACS Publications website at DOI: 10.1021/acs.iecr.6b02752.

Steady-state validation results for $70 \%$ (Table S1) and $50 \%$ (Table S2) load for the carbon capture plant (PDF)

\section{AUTHOR INFORMATION \\ Corresponding Author}

*E-mail: thomas.marx@tuhh.de. Phone: +49 (0)40 428783079.

Notes

The authors declare no competing financial interest.

\section{ACKNOWLEDGMENTS}

This research project has been supported by the Federal Ministry of Economics and Technology (Project 03ET2009), which is greatly acknowledged.

\section{NOMENCLATURE}

$$
\begin{aligned}
& \alpha=\text { solvent loading }\left(\mathrm{mol}_{\mathrm{CO}_{2}} / \mathrm{mol}_{\mathrm{MEA}}\right) \\
& \dot{m}=\text { mass flow rate }(\mathrm{kg} / \mathrm{h}) \\
& \dot{N}=\text { mole flow rate }(\mathrm{mol} / \mathrm{h}) \\
& \dot{Q}=\text { heat flow rate }(\mathrm{W}) \\
& p=\text { pressure }(\mathrm{mbar} \text { or bar }) \\
& q_{\text {spec }}=\text { specific energy demand }\left(\mathrm{MJ} / \mathrm{kg}_{\mathrm{CO}_{2}}\right) \\
& T=\text { temperature }\left({ }^{\circ} \mathrm{C} \text { or } \mathrm{K}\right) \\
& X=\mathrm{CO}_{2} \text { capture rate }(\%) \\
& \mathrm{CCS}=\text { carbon capture and storage } \\
& \mathrm{HP}=\text { high pressure } \\
& \mathrm{IP}=\text { intermediate pressure } \\
& \mathrm{LP}=\text { low pressure } \\
& \mathrm{MEA}=\text { monoethanolamine } \\
& \mathrm{PCC}=\text { postcombustion carbon capture } \\
& \text { PFD = process flow diagram } \\
& \text { abs }=\text { absorber } \\
& \text { lean }=\mathrm{CO}_{2} \text {-lean condition } \\
& \text { reb = reboiler } \\
& \text { rich = CO } \mathrm{CO}_{2} \text {-rich condition } \\
& \text { str }=\text { stripper }
\end{aligned}
$$

\section{REFERENCES}

(1) IPCC (Intergovernmental Panel on Climate Change). Special Report on Carbon Dioxide Capture and Storage; Cambridge University Press: Cambridge, 2005.

(2) IEA (International Energy Agency. World Energy Outlook Special Report: Redrawing the Energy-Climate Map; International Energy Agency: Paris, 2013; pp 113-115.

(3) Bui, A.; Gunawan, I.; Verheyen, V.; Feron, P.; Meuleman, E.; Adeloju, S. Dynamic modelling and optimization of flexible operation 
in post-combustion $\mathrm{CO}_{2}$ capture plants-A review. Comput. Chem. Eng. 2014, 61, 245-265.

(4) Posch, S.; Haider, M. Dynamic modeling of $\mathrm{CO}_{2}$ absorption from coal-fired power plants into an aqueous monoethanolamine solution. Chem. Eng. Res. Des. 2013, 91, 977-987.

(5) Lawal, A.; Wang, M.; Stephenson, P.; Yeung, H. Dynamic modelling of $\mathrm{CO}_{2}$ absorption for post combustion capture in coal-fired power plants. Fuel 2009, 88, 2455-2462.

(6) Kvamsdal, H. M.; Chikukwa, A.; Hillestad, M.; Zakeri, A.; Einbu, A. A comparison of different parameter correlation models and the validation of an MEA-based absorber model. Energy Procedia 2011, 4, $1526-1533$.

(7) Jayarathna, S. A.; Lie, B.; Melaaen, M. C. Dynamic modelling of the absorber of a post combustion $\mathrm{CO}_{2}$ capture plant: modelling and simulations. Comput. Chem. Eng. 2013, 53, 178.

(8) Montañés, R. M.; Korpås, M.; Nord, L. O.; Jaehnert, S. Identifying operational requirements for flexible CCS power plant in future energy systems. Energy Procedia 2016, 86, 22-31.

(9) Oexmann, J. Post-Combustion $\mathrm{CO}_{2}$ Capture: Energetic Evaluation of Chemical Absorption Processes in Coal-Fired Steam Power Plants. Dissertation, University Hamburg-Harburg, Institute of Energy Systems, Hamburg, 2011. ISBN 978-3-86955-633-8.

(10) Hilliard, M. A Predictive Thermodynamic Model for an Aqueous Blend of Potassium Carbonate, Piperazine, and Monoethanolamine for Carbon Dioxide Capture from Flue Gas. Ph.D. Dissertation, University of Texas at Austin, 2008.

(11) Wappel, D.; Gronald, G.; Kalb, R.; Draxler, J. Ionic liquids for post-combustion $\mathrm{CO}_{2}$ absorption. Int. J. Greenhouse Gas Control 2010, 4, 486-494.

(12) Modelica, version 3.3. 2014; http://www.modelica.org.

(13) Dietl, K. Equation-based object-oriented modelling of dynamic absorption and rectification processes. Dissertation, Hamburg University of Technology, 2012.

(14) Dietl, K.; Joos, A.; Schmitz, G. Dynamic analysis of the absorption/desorption loop of a carbon capture plant using an objectoriented approach. Chem. Eng. Process. 2012, 52, 132-139.

(15) Aspen Plus. Aspen Technology, Inc.: Burlington, MA, 2011; http://www.aspentech.com/uploadedFiles/Products/Templates/ Aspen_Plus.pdf.

(16) Stichlmair, J.; Bravo, J.; Fair, J. General model for prediction of pressure drop and capacity of countercurrent gas/liquid packed columns. Gas Sep. Purif. 1989, 3, 19-28.

(17) ClaRa Research Team, Homepage of the ClaRa model library. http://www.clarasim.com.

(18) Meier, H.-J.; Alf, M.; Fischedick, M.; Hillebrand, B.; Lichte, H.; Meier, J.; Neubronner, M.; Schmitt, D.; Victor, W.; Wagner, M. Reference Power Plant North Rhine-Westfalia (RPP NRW). VGB Power Tech 2004, 5, 76-89.

(19) VFF GmbH \& Co. KG, Manufacturer of random packings for pilot plant. http://www.vff.de/en/products/random-packings.

(20) Rieder, A.; Unterberger, S. EnBW's post-combustion capture pilot plant ar Heilbronn - Results of the first year's testing programme. Energy Procedia 2013, 37, 6464-6472.

(21) Lucquiaud, M.; Gibbins, J. On the integration of $\mathrm{CO}_{2}$ capture with coal-fired power plants: A methodology to assess and optimize solvent-based post-combustion capture systems. Chem. Eng. Res. Des. 2011, 89, 1553-1571.

(22) Sanpasertparnich, T.; Idem, R.; Bolea, I.; deMontigny, D.; Tontiwachwuthikul, P. Integration of post-combustion capture and storage into a pulverized coal-fired power plant. Int. J. Greenhouse Gas Control 2010, 4, 499-510.

(23) Linnenberg, S.; Darde, V.; Oexmann, J.; Kather, A.; van Well, W. J.; Thomsen, K. Evaluating the impact of an ammonia-based postcombustion $\mathrm{CO}_{2}$ capture process on a steam power plant with different cooling water temperatures. Int. J. Greenhouse Gas Control 2012, 10, 1-14.

(24) Oexmann, J.; Kather, A. Post-combustion $\mathrm{CO}_{2}$ capture in coalfired power plants: Comparison of integrated chemical absorption processes with piperazine promoted potassium carbonate and MEA Energy Procedia 2009, 1, 799-806.

(25) Oexmann, J.; Kather, A.; Linnenberg, S.; Liebenthal, U. Postcombustion $\mathrm{CO}_{2}$ capture: chemical absorption processes in coal-fired steam power plants. Greenhouse Gases: Sci. Technol. 2012, 2, 80-98.

(26) Pfaff, I.; Oexmann, J.; Kather, A. Optimised integration of postcombustion $\mathrm{CO}_{2}$ capture process in greenfield power plants. Energy 2010, 35, 4030-4041.

(27) Liebenthal, U.; Linnenberg, S.; Oexmann, J.; Kather, A. Derivation of correlations to evaluate the impact of retrofitted postcombustion $\mathrm{CO}_{2}$ capture processes on steam power plant performance. Int. J. Greenhouse Gas Control 2011, 5, 1232-1239.

(28) Davis, J.; Rochelle, G. Thermal degradation of monoethanolamine at stripper conditions. Energy Procedia 2009, 1, 327-333.

(29) Schulze, S. Continuous Modulating Actuators Improve Plant Efficiency. http://www.power-eng.com/articles/print/volume-116/ issue-8/features/continuous-modulating-actuators.html (accessed September 9,2014 ).

(30) Gottelt, F.; Wellner, K.; Roeder, V.; Brunnemann, J.; Schmitz, G.; Kather, A. A Unified Control Scheme for Coal-Fired Power Plants with Integrated Post Combustion $\mathrm{CO}_{2}$. IFAC Proceedings Volumes 2012, 45 (21), 284-289. 